\title{
Cleft palate-stapes fixation-oligodontia syndrome
}

INSERM

\section{Source}

INSERM. (1999). Orphanet: an online rare disease and orphan drug data base. Cleft palate-stapes fixation-oligodontia syndrome. ORPHA:2010

Cleft palate - stapes fixation - oligodontia is characterized by cleft soft palate, severe oligodontia of the deciduous teeth, absence of the permanent dentition, bilateral conductive deafness due to fixation of the footplate of the stapes, short halluces with a wide space between the first and second toes, and fusion of carpal and tarsal bones. It has been described in two sisters of Swedish extraction. An autosomal recessive mode of inheritance is likely. There have been no further descriptions in the literature since 1971. 